\title{
Parallel processing in the brain's visual form system: an fMRI study
}

\section{Yoshihito Shigihara and Semir Zeki*}

Wellcome Laboratory of Neurobiology, University College London, London, UK

\section{Edited by:}

Aron K. Barbey, University of Illinois at Urbana-Champaign, USA

\section{Reviewed by:}

Roberto Martuzzi, Ecole

Polytechnique Fédérale de

Lausanne, Switzerland

Aron K. Barbey, University of Illinois

at Urbana-Champaign, USA

*Correspondence:

Semir Zeki, Wellcome Laboratory of Neurobiology, University College

London, Gower Street, London

WC1E 6BT, UK

e-mail:s.zeki@ucl.ac.uk
We here extend and complement our earlier time-based, magneto-encephalographic (MEG), study of the processing of forms by the visual brain (Shigihara and Zeki, 2013) with a functional magnetic resonance imaging (fMRI) study, in order to better localize the activity produced in early visual areas when subjects view simple geometric stimuli of increasing perceptual complexity (lines, angles, rhombuses) constituted from the same elements (lines). Our results show that all three categories of form activate all three visual areas with which we were principally concerned (V1-V3), with angles producing the strongest and rhombuses the weakest activity in all three. The difference between the activity produced by angles and rhombuses was significant, that between lines and rhombuses was trend significant while that between lines and angles was not. Taken together with our earlier MEG results, the present ones suggest that a parallel strategy is used in processing forms, in addition to the well-documented hierarchical strategy.

Keywords: hierarchy, early visual areas, fMRI, retinotopic mapping, parallel processing, form vision, dynamic parallelism

\section{INTRODUCTION}

Ever since their discovery by Hubel and Wiesel (1959), the orientation selective (OS) cells of the primary visual cortex (area V1) have been considered to be the source of the physiological building blocks for the elaboration of forms in the visual brain (Hubel and Wiesel, 1977; Riesenhuber and Poggio, 1999; Lerner et al., 2001; Nandy et al., 2013, inter alia). That there is a physiological hierarchy in the properties of OS cells, with some having more complex properties than others, has encouraged a belief in the hierarchical doctrine, which supposes that forms are elaborated sequentially, with OS cells of simpler physiological properties feeding into OS cells with more complex ones, either in different layers of the same visual area (principally V1) or in successive visual areas, such as V2 and V3 (Hubel and Wiesel, 1962, 1965).

Apart from differences in complexity of the physiological properties of OS cells at successive stages (layers) in area V1 and between $\mathrm{V} 1$ and visual areas of the prestriate cortex, there is much anatomical and physiological evidence to support the hierarchical doctrine. The evidence comes in part from anatomy, with the predominant visual input from the retina terminating in area V1, where OS cells are first elaborated. It comes also from physiological studies which have traced a hierarchical, constructivist, relationship between simple and complex OS cells (Hubel and Wiesel, 1962, 1965; Alonso and Martinez, 1998; Martinez and Alonso, 2001; Finn and Ferster, 2007, inter alia). Finally, the serial connections between area V1 and areas V2 and V3 (Cragg, 1969; Zeki, 1969, 1971; Zeki and Shipp, 1988; Van Essen et al., 1986; Rockland, 1992; Burkhalter, 1993) are also consistent with a hierarchical model, in which OS cells of increasing complexity are not uniformly distributed in these visual areas but cells with more complex properties are rather preferentially distributed in areas outside V1 (Hubel and Wiesel, 1965). Mirroring this physiological hierarchy is a temporal hierarchy, reflected in the fact that cells of V1 respond with shorter latencies than cells of the prestriate visual cortex (Raiguel et al., 1989; Maunsell and Gibson, 1992; Lamme and Roelfsema, 2000).

There is however also reliable anatomical and physiological evidence to suggest that, in addition to the hierarchical strategy, the brain may also use a parallel one to elaborate forms. Anatomical evidence has established that, in addition to the inputs from V1 to prestriate areas such as V2 and V3 (Cragg, 1969; Zeki, 1969), there is a direct projection from subcortical visual nuclei such as the pulvinar and the lateral geniculate nucleus (LGN) to prestriate visual areas, including areas V2, V3, V4, and V5 (Cragg, 1969; Benevento and Rezak, 1976; Benevento and Yoshida, 1981; Fries, 1981; Yukie and Iwai, 1981; Bullier and Kennedy, 1983; Kennedy and Bullier, 1985; ffytche et al., 1995; Sincich et al., 2004; Leh et al., 2008; Baldwin et al., 2012; Cortes and Van Vreeswijk, 2012). This "V1-bypassing" input can sustain a weakened visual activity in V2 and V3 even in the absence of V1, with cells in both areas deprived of a V1 input still displaying orientation selectivity (Schmid et al., 2012). There is, as well, physiological evidence to show that OS cells with tunings similar to those in V1 but with larger receptive fields are widely distributed in the primate visual brain, and constitute heavy concentrations in V2, V3, and V3A (Zeki, 1978; Larsson et al., 2010), thus raising the question of what further contribution these cells make to the elaboration of forms. Moreover, latency studies have shown that, when appropriately tailored to the functional requirements of prestriate visual areas, the latency elicited in a prestriate area such as V5 may actually precede that in V1 (or V2) (ffytche et al., 1995; Schoenfeld et al., 2002; Gaglianese et al., 2012). This 
evidence made it interesting for us to investigate the possibility that a parallel strategy, whose source is not confined to V1, is also used by the brain to elaborate forms.

Our enquiry into a parallel contribution to the processing of forms began with a time-based magnetoencephalograpic (MEG) study (Shigihara and Zeki, 2013), which showed that two forms of increasing perceptual hierarchy-lines and rhombuses constituted from them-activate V1 and the early visual areas of prestriate cortex within the same time frame (at between 27 and $44 \mathrm{~ms}$ ). Here, we extend that study by using functional magnetic resonance imaging (fMRI), to compensate for the relatively low spatial resolution of MEG and thus to better localize the activity produced in prestriate cortex. In doing so, we also enlarged the repertoire of forms viewed. In our MEG study, we had chosen lines because of the ubiquity of OS cells in areas V1-V3, and rhombuses consisting of the same lines because they are perceptually more complex. In this one, we added angles partly because they are intermediate in perceptual hierarchy between lines and rhombuses and partly because rhombuses have angles as constituents, which have been considered to be potent stimuli for cells in V2 (Hegdé and Van Essen, 2000; Ito and Komatsu, 2004), thus raising the possibility that they may activate human V2 more strongly than lines. Our general hypothesis, derived from our MEG studies, was that all three forms derived from straight lines will activate all the three visual areas with which we are principally concerned equally.

\section{MATERIALS AND METHODS SUBJECTS}

Nine right-handed healthy adult volunteers ( 5 female, mean age 29.2 years) took part. All had also participated in our previous study using MEG. The activity in the brains of 11 further subjects, who had also taken part in the MEG study, was also studied using the identical stimuli and paradigm except that we did not obtain retinotopic maps for them. Data from these 11 subjects are shown separately in the Supplementary Data. None of the subjects had a history of neurological or psychiatric disorder; written informed consent was obtained from all and the study was approved by the Ethics Committee of University College London.

\section{STIMULI AND TASK}

In general, we tried to keep our stimulus presentation and paradigm as similar to the ones we used in our MEG study, to allow for a direct comparison. The stimuli were generated in the same way as in our previous MEG study (Shigihara and Zeki, 2013) but differed in (a) the addition of a further category (angles) constituted from the same lines and intermediate in perceptual complexity between lines and rhombuses and (b) a reduction in the size of all the form stimuli by $14 \%$, because of the smaller $\mathrm{fMRI}$ scanner screen size. To match our previous study MEG study, subjects viewed the fixation cross (subtending $0.9 \times$ $0.9^{\circ}$ ) at the center of the screen monocularly with the right eye (a patch covered the left eye). All stimuli were displayed separately in either the lower left (nasal) or lower right (temporal) quadrants of the visual field, between 1.1 and $10.5^{\circ}$ below the fixation cross and $1.9-11.8^{\circ}$ on either side. Three different form stimuli

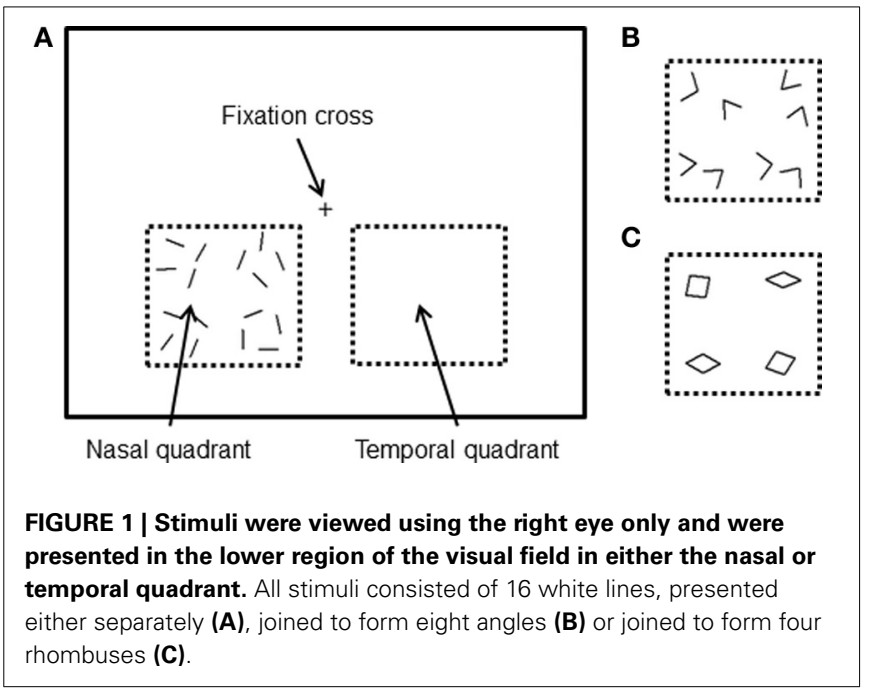

were used: 16 lines, 8 angles, or 4 rhombuses (Figures 1A-C), all consisting of the same16 white lines. The vertices of angled stimuli varied from 54 to $108^{\circ}$ and those of rhombuses from 18 to $162^{\circ}$. The same image (e.g., oriented lines) flashed at $8 \mathrm{~Hz}(67 \mathrm{~ms}$ between flashes) without changing the orientation of the line, to maximize the activation during the scans (Kwong et al., 1992); it continued to flash for $4 \mathrm{~s}$, then disappeared and was replaced by a new stimulus which could be another oriented line or one of the two other categories (angles and rhombuses), the sequence being randomized.

There were four 5-min runs; each had 63 stimulus periods of $4 \mathrm{~s}$ duration. After every 21 stimuli there was a $20 \mathrm{~s}$ rest period, which served as baseline. The sequences of six different conditions ( 2 quadrants $\times 3$ forms) were pseudo-randomized and counterbalanced across runs and participants. To reduce participants' eye movements and maintain their attention, the fixation cross periodically increased its vertical size from 0.9 to $1.1^{\circ}$ for a brief interval $(100 \mathrm{~ms})$, which subjects were asked to report by pressing a button with their right index finger.

\section{SCANNING DETAILS}

Scanning was done in a 3.0-T Siemens Magnetron Allegra MRI scanner (Siemens, Erlangen, Germany). There were two scanning sessions, functional and retinotopic, the latter to identify the borders between V1, dorsal V2, and dorsal V3 (V2d and V3d, respectively) since we presented our stimuli in the lower quadrants only. Each run of the functional and retinotopic mapping sessions began with a blank screen (black for the functional session, gray for the retinotopic) for $\sim 17 \mathrm{~s}$; the first six brain volumes acquired were subsequently discarded to allow for T1 equilibration effects. An echo-planar imaging (EPI) sequence was applied to obtain Blood-oxygen-level dependent (BOLD) signal (echo time $\mathrm{TE}=30 \mathrm{~ms}$, repeat time $\mathrm{TR}=2.88 \mathrm{~s}$ ) using 48 slices to cover the whole brain. The voxel resolution was $3 \times 3 \mathrm{~mm}$ in-plane resolution, with a $2 \mathrm{~mm}$ slice thickness and $1 \mathrm{~mm}$ inter-slice gap. A T1-weighted anatomical image was acquired for each subject (176 slices, resolution $1 \times 1 \times 1 \mathrm{~mm}, \mathrm{TE}=2.48 \mathrm{~ms}$, TR $=7.92 \mathrm{~ms}$ ) between those scans. 


\section{FUNCTIONAL SESSIONS}

Functional images were pre-processed and analyzed using SPM-8 (http://www.fil.ion.ucl.ac.uk/spm). They were realigned to the first volume of the first experimental session, and re-sliced to a final voxel resolution of $3 \times 3 \times 3 \mathrm{~mm}^{3}$ to match the functional and retinotopic scans because, for some subjects, the two scans were performed on separate days. Normalization and smoothing were not applied because the data are based on individual brains. The stimulus for each subject was modeled as a set of regressors in a general linear model (GLM). Boxcar function was used to define stimulus functions, which modeled the onsets and durations of each stimulus period. Head movement parameters calculated from the realignment pre-processing step were included as regressors of no interest. Stimulus functions were convolved with a canonical Hemodynamic Response Function to provide regressors for the GLM. Contrast images for each form vs. baseline were made and used to evaluate average activity in each visual area (described below).

\section{RETINOTOPIC MAPPING}

In this study, we are especially interested in three early visual areas: V1, V2d, and V3d; we used retinotopic mapping techniques to identify their borders and make region of interest (ROI) masks to cover them. The scan for retinotopic mapping consisted of two $8 \mathrm{~min}$ runs, one with a clockwise and the other an anti-clockwise stimulus direction. Individual retinotopic maps were obtained from all nine subjects because of individual differences in the position and borders of early visual areas (Stensaas et al., 1974). Retinotopic mapping stimuli were generated with scripts written by Schwarzkopf (http://www.fil.ion.ucl.ac.uk/ $\sim$ sschwarz/retinotopy.html) for MATLAB and Psychtoolbox-3
(http://psychtoolbox.org/HomePage) and using the same projector as the functional stimuli. A rotating wedge-shaped stimulus containing an expanding color ripple pattern was used (Figure 2A). To make ROI masks for areas V1, V2d, and V3d in each subject, EPI images from the retinotopic sessions were transformed to phase space (phase maps) using phase-encoded retinotopic mapping techniques (Sereno et al., 1995) and averaged with scripts written by Schwarzkopf (http://www.fil.ion.ucl.ac.uk/ sschwarz/retinotopy.html). These phase maps were then overlaid onto an inflated anatomical brain image which had been created individually for each subject using FreeSurfer (http://surfer.nmr.mgh.harvard.edu/). The boundaries of V1, V2d, and V3d were then manually delineated by identifying the representation of the meridians from the mirror reversals in the phase map (Figure 2B). As our interest was focused on V1, V2d, and V3d we did not extend our retinotopic mapping to areas $\mathrm{V} 3 \mathrm{~A}$ and $\mathrm{V} 3 \mathrm{~B}$.

\section{EVALUATING AVERAGE ACTIVATION INTENSITY IN EACH VISUAL AREA (ROI ANALYSIS)}

The average activation intensity of all voxels in each of the three visual areas of the contralateral hemisphere was obtained from the results of the contrast images (each form vs. baseline) and from ROI masks (V1, V2d, and V3d) during the retinotopic session for each subject, further broken down by form and quadrant. A three-way (area $\times$ form $\times$ quadrant) repeated measures ANOVA was applied, followed by post-hoc $t$-tests. The Ryan method (Ludbrook, 1991) was used to make multiple comparisons. To confirm that all three forms activate all three areas, a one sample $t$-test was used after combining activation intensities across areas and quadrants, since a three-way repeated measures ANOVA had shown no main effect of area and quadrant and

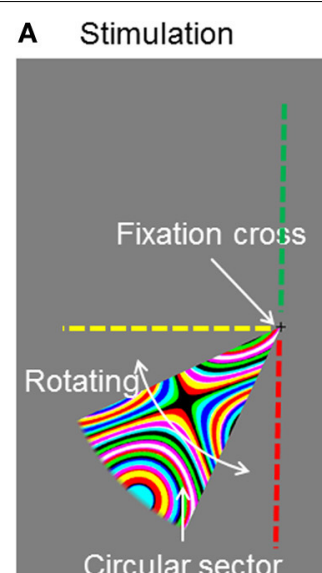

Circular sector
B ROls on an inflated brain image

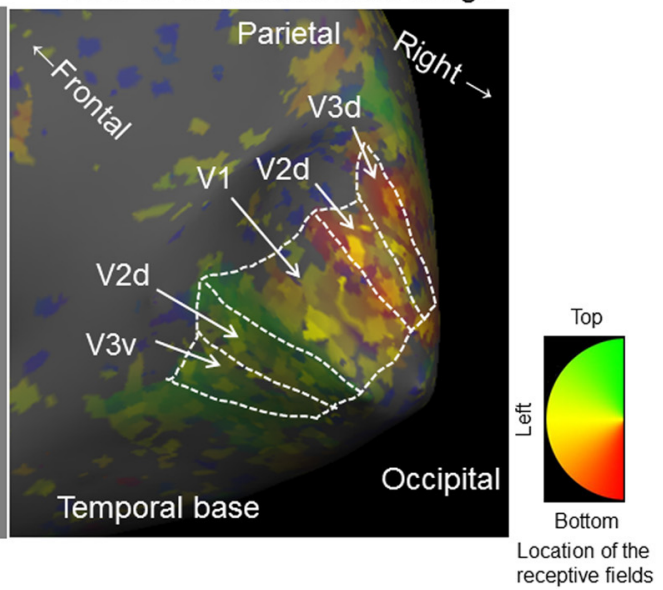

FIGURE 2 | Stimulation for obtaining retinotopic maps and charting region of interest on an inflated brain image for a typical single subject. (A) Stimulus: A circular sector (central angle $40^{\circ}$ ) sustaining $8^{\circ}$ and rotated in either a clockwise or anticlockwise direction for eight cycles at an angular velocity of 61.2 seconds per cycle. The sector was filled with a dynamically expanding colored ripple pattern. Green, yellow and red broken lines indicate the upper vertical left horizontal and lower vertical lines of the screen. (B) Retinotopicaly identified ROls for $\mathrm{V} 1-\mathrm{V} 3$ on an inflated anatomical brain image (Right hemisphere): The colored overlay image is a phase map which represents the brain area responding to the stimulus location on the screen. The borders for each ROI were manually identified. d, dorsal; v, ventral. 
no interactions. $P$-values were two-tailed, with $P$-values less than 0.05 considered significant.

\section{RESULTS \\ RETINOTOPIC MAPPING}

The vertical meridian is represented at the border between V1 and $\mathrm{V} 2$, a representation of the horizontal meridian demarcates the border between V2 and V3 while the vertical meridian is represented again at the anterior border of $\mathrm{V} 3$, in both monkey and human brains (Cragg, 1969; Zeki, 1969; Shipp et al., 1995; Tootell et al., 1997, Figure 2). We were able to identify these borders in all subjects with our retinotopic mapping, and thus locate the three areas that we are concerned with retinotopically. This allowed us to learn whether each area was activated by the three categories of form stimuli used.

\section{ACTIVATION BY THE THREE FORMS}

A typical activation map is shown in Figure 3. The activation produced by each category of form stimulus covered all three visual areas (V1-V2d-V3d).

To evaluate the intensity of activation in each of the three visual areas, we calculated the intensity of activation within each retinotopically mapped area (Figure 4 and Table 1). One sample $t$-tests showed that all three forms produced significant activations relative to baseline in each area (Table 1: each form: $P<0.05$ ). To determine which factors (quadrant, visual area, and form) modulate the intensities of activations, we employed a three-way repeated measures ANOVA (quadrant $\times$ area $\times$ form: Table 2). This showed a main effect of form, but not of area or quadrant and no interactions. Hence there were differences in average activation produced by lines, angles and rhombuses but none in average activation between visual areas or in the visual quadrant (lower nasal or temporal) stimulated. In terms of form, posthoc $t$-tests showed that angles produced significantly stronger

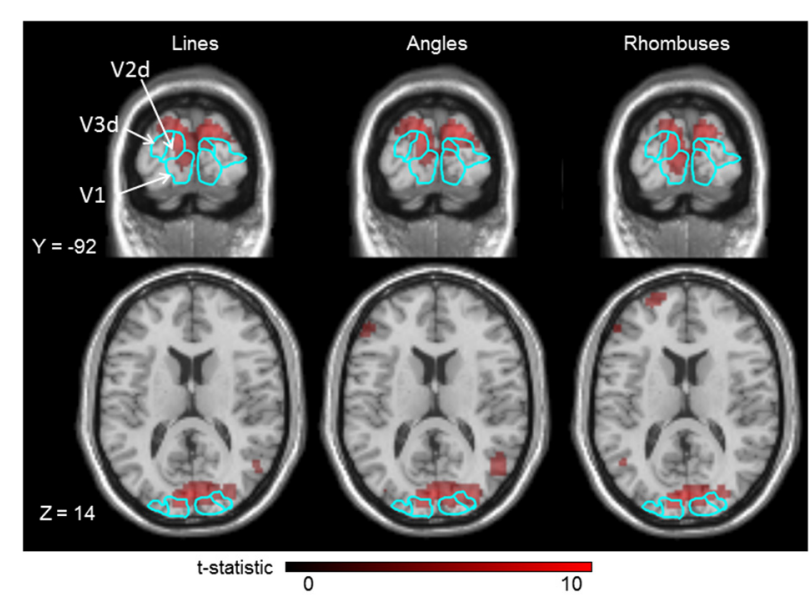

FIGURE 3 | Cortical activations produced in the three visual areas (V1-V3) by lines, angles, and rhombuses vs. baseline, for a typical single subject, superimposed on his anatomical brain image.

Smoothing was not applied. Borders of those visual areas are displayed in light blue lines. Displayed threshold of $P(\mathrm{FWE})<0.05$ activations than rhombuses $(P=0.006)$ for all three areas. The difference between the activity produced by angles and rhombuses was trend significant $(P=0.066)$ while that between lines and angles was not $(P=0.254)$ (Table 2$)$. In summary, all three forms activated all three areas and angles produced the strongest activation in each visual area.

\section{ADDITIONAL SCANS}

All 20 subject who were enrolled in our previous MEG study (Shigihara and Zeki, 2013) were also scanned functionally. The details are shown in the Supplementary data. In brief, whether we use 9 or 20 subjects, group analysis shows that all three forms activated both striate and prestriate cortices and that the strengths of activation produced by the three forms were similar.

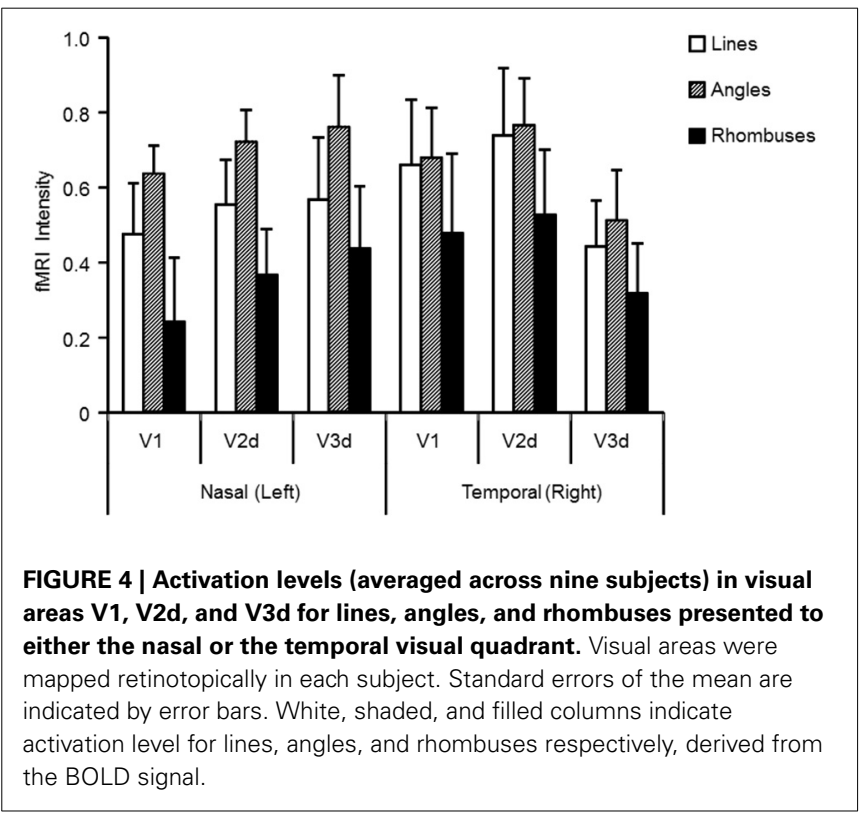

Table 1 | Results of one sample $t$-test comparisons of Blood-oxygen-level dependent signal intensities associated with areas and forms across nine subjects.

\begin{tabular}{lllc}
\hline Area & Form & Statistics & $\boldsymbol{P}$ \\
\hline V1 & Line & $t_{(17)}=5.158$ & $7.89 \mathrm{E}-05$ \\
& Angle & $t_{(17)}=9.054$ & $6.50 \mathrm{E}-08$ \\
& Rhombus & $t_{(17)}=2.675$ & $1.60 \mathrm{E}-02$ \\
\hline V2d & Line & $t_{(17)}=6.044$ & $1.32 \mathrm{E}-05$ \\
& Angle & $t_{(17)}=10.211$ & $1.14 \mathrm{E}-08$ \\
& Rhombus & $t_{(17)}=4.246$ & $5.45 \mathrm{E}-04$ \\
\hline V3d & Line & $t_{(17)}=5.078$ & $9.32 \mathrm{E}-05$ \\
& Angle & $t_{(17)}=6.554$ & $4.91 \mathrm{E}-06$ \\
& Rhombus & $t_{(17)}=3.611$ & $2.16 \mathrm{E}-03$
\end{tabular}

Blood-oxygen-level dependent signal intensities (vs. baseline) were averaged within each visual area in contra-lateral hemisphere and were combined across quadrants. A one sample t-test showed that all three forms produced significant activations in all areas. 
Table 2 | Results of Three-Way ANOVA comparisons of Blood-oxygen-level dependent intensities associated with quadrants, areas and forms across nine subjects.

\begin{tabular}{llcc}
\hline & & \multicolumn{1}{c}{ Statistic } & $\boldsymbol{P}$ \\
\hline Main effect & Quadrant & $F_{(1,8)}=0.136$ & $7.22 \mathrm{E}-01$ \\
& Area & $F_{(2,16)}=0.822$ & $4.57 \mathrm{E}-01$ \\
& Form & $F_{(2,16)}=5.092$ & $\mathbf{1 . 9 4 E - 0 2}$ \\
\hline Interaction & Quadrant-area & $F_{(2,16)}=2.114$ & $1.53 \mathrm{E}-01$ \\
& Quadrant-form & $F_{(2,16)}=1.030$ & $3.80 \mathrm{E}-01$ \\
& Area-form & $F_{(4,32)}=0.625$ & $6.48 \mathrm{E}-01$ \\
& Quadrant-area-form & $F_{(4,32)}=0.462$ & $7.63 \mathrm{E}-01$ \\
\hline Post-hoc & Angle $>$ rhombus & $t=3.158$ & $\mathbf{6 . 0 9 E}-03$ \\
& Angle $>$ line & $t=1.184$ & $2.54 \mathrm{E}-01$ \\
& Line $>$ rhombus & $t=1.974$ & $6.59 \mathrm{E}-02$
\end{tabular}

Blood-oxygen-level dependent intensities (vs. baseline) were averaged within each area in the contra-lateral hemisphere. A Three-Way ANOVA showed that forms modulate averaged intensities. Post-hoc t-test showed that the averaged intensity for angles was significantly stronger than for rhombuses regardless of quadrants and areas. Bold digits indicate significant difference $(P<0.05)$.

\section{DISCUSSION}

Areas V2 and V3 of the primate visual brain surround area V1, generally considered to be the first and most prominent recipient of visual signals in the cortex, and are prominently connected with it (Cragg, 1969; Zeki, 1969, inter alia). This anatomical arrangement as well as the sequence of latencies in the areas provoked by visual stimulation (Lamme and Roelfsema, 2000 for a review) reinforces support for the hierarchical doctrine of form perception, which supposes that OS cells of V1 are the source of the physiological building blocks of form, from which further, more complex, forms are elaborated. As we point out in the Introduction, there is much to support such a claim. But, in the work reported here, we set out to extend our earlier time-based study using MEG (Shigihara and Zeki, 2013), to learn whether there is not, in addition, a parallel strategy in the construction of form involving these three areas. The results reported here, taken together with our earlier MEG evidence, lead us to suspect that a parallel strategy, whose source may not be confined to V1, may also be used to elaborate forms, in addition to the well-documented hierarchical strategy.

\section{PARALLEL AND HIERARCHICAL STRATEGIES}

It is perhaps instructive to begin by laying out what result, given our stimuli and the paradigm we have used, the hierarchical and parallel strategies would predict.

A strictly hierarchical strategy would predict that three visual areas with which we are principally concerned (V1-V3) should not be activated with the same strength by all the three forms. Instead, one might expect rhombuses to produce the strongest response, since they have the constituent oriented lines plus a more complex form built from them, while simple oriented lines might be expected to produce the weakest activity. Alternatively, if there is an uneven distribution of cells of differing complexity between the three areas (Hubel and Wiesel, 1965), one might expect that the simplest form-oriented lines-will activate the "earlier" visual area, V1, more strongly while rhombuses will activate "later" visual areas (e.g., V3) more strongly. As well, the hierarchical strategy would predict that the latency of activation should be briefest for simple lines and longest for the perceptually more complex rhombuses, with angles falling somewhere in between.

By contrast, the parallel model would predict that (a) all three forms should activate all three visual areas and that each form should do so with more or less equal strength; (b) that the three different forms should activate the cortex with similar latencies.

In fact, the results we obtained support and give credence to the utilization of a parallel strategy to construct forms. All three forms activated all three visual areas, each form activating each visual area with the same strength although, overall, angles produced the strongest activation in all three areas and rhombuses the weakest. These results are consistent with our earlier, timebased results (Shigihara and Zeki, 2013) which showed that (a) lines and rhombuses produced very early responses (between 27 and $44 \mathrm{~ms}$ ) in occipital areas; (b) the sources of the responses were estimated (localized) in both striate (V1) and prestriate cortices; (c) in the MEG study, the response amplitude for lines was stronger than that for rhombuses, implying a more powerful activation produced by lines than by rhombuses, which is the opposite of what one might expect from an exclusive hierarchical strategy. When we say that this evidence supports the possibility that a parallel strategy is also used to construct forms, we do so without implying that a hierarchical strategy is not used. Our principal and sole aim here was to explore the extent to which a parallel strategy may be used to construct forms; it was not aimed at documenting the evidence in favor of a hierarchical strategy, which has been documented many times, or to determine which of the two strategies is the more potent one.

\section{PARALLEL VISUAL INPUTS TO V1 AND PRESTRIATE CORTEX: EVIDENCE FROM ANATOMY AND LATENCY STUDIES}

That there are parallel strategies within visual cortex itself, implied by the parallel anatomical connections from V1 and V2 (which are themselves interconnected) to, say, V4 and V5 (Zeki and Shipp, 1988), has long been acknowledged and its computational significance evaluated (e.g., Zeki, 1976; Ballard et al., 1983; Grossberg, 1991). Much less attention has been given to parallel inputs to V1 and areas of the prestriate cortex from sub-cortical visual stations such as the LGN and the pulvinar, though it has received some recently (Cortes and Van Vreeswijk, 2012). This is surprising since such pathways have been known to exist for a relatively long time from LGN (Cragg, 1969; Fries, 1981; Yukie and Iwai, 1981) and pulvinar (Cragg, 1969; Benevento and Rezak, 1976; Baldwin et al., 2012), and their capacity to mediate a crude but conscious experience of vision acknowledged (Barbur et al., 1993; Sahraie et al., 1997; Zeki and ffytche, 1998; Schoenfeld et al., 2002). Perhaps this neglect is due to the dominant role played by the classical geniculate to V1 pathway, lesions in which lead to blindness commensurate with the size and position of the lesion. Yet there is also evidence that lesions restricted to V2 and V3 lead to a comparable blindness (Horton and Hoyt, 1991), although 
such evidence is sparse because much more difficult to obtain due to the disposition of $\mathrm{V} 2$ and $\mathrm{V} 3$ in relation to $\mathrm{V} 1$, which means that damage to the latter usually also involves damage to the former. Perhaps it is due as well to latency studies, which have commonly used flash stimuli to evoke responses from cortex and which, collectively, have shown that activity in V1 precedes that in prestriate visual areas (see Lamme and Roelfsema, 2000 for a review). But when stimuli are better tailored to the properties of individual areas of the prestriate cortex, a more complex picture emerges, in which prestriate areas may receive visual input earlier than V1, depending on the nature of the stimulus, as in the example of V5 (ffytche et al., 1995; Gaglianese et al., 2012). The dual input to V5 from the sub-cortex (ffytche et al., 1995; Sincich et al., 2004), one mediated through V1 and the other by-passing $\mathrm{V} 1$ and terminating directly in V5, was demonstrated by using stimuli that differed in speed, with fast moving stimuli activating V5 before activating V1, leading to the concept of a dynamic parallelism (Beckers and Zeki, 1995; ffytche et al., 1995). Hence, it becomes plausible to suppose that these direct inputs to visual areas of the prestriate cortex with large concentrations of OS cells may deliver signals related to form vision directly to V2 and V3 and V3A, without passing through V1 (Schmid et al., 2012), just as they deliver motion-related signals directly to V5 (ffytche et al., 1995; Schoenfeld et al., 2002; Sincich et al., 2004). Once again, we emphasize that a parallel system must be integrated with the hierarchical system; this is indeed implicit in the demonstration that, although cells in V2 and V3 are reactive to the appropriate visual stimuli in the absence of V1, the strength of activity in them is significantly reduced (Schmid et al., 2012).

\section{LIMITATIONS OF OUR STUDY \\ Stimuli}

There are many different ways of stimulating the visual form system and we do not pretend to have used the optimal stimuli for activating all three visual areas, V1-V3, in this study. We could, for example, have used pictures of real objects or Glass patterns (Ostwald et al., 2008). We tailored our stimuli as best we could to the reported physiology of these areas, which shows that all three contain heavy concentrations of OS cells (Zeki, 1978; Larsson et al., 2006, 2010). More generally, our concern was mainly with OS cells and whether an exclusive hierarchical strategy is used to integrate their responses into more elaborate forms, sequentially and hierarchically.

Our stimuli nevertheless reveal an interesting feature, which may yet turn out to be significant. Although we obtained a significant difference in strength of activity produced by angles and rhombuses, the difference in strength between lines and angles was not significant, in that they both activated the three visual areas with similar strengths. This is mirrored in psychophysical masking studies (Lo and Zeki, 2014), in which we found that angles and rhombuses do not mask each other significantly (implying independent processing of the two, see Cheadle and Zeki, 2011) while lines and angles do. This implies that lines and angles may belong to the same family of forms, distinct from the more complex rhombuses, even if-as our current evidence suggests - angles and lines may be processed in parallel within the three visual areas.

\section{Possible confounds due to the density of the stimuli}

A possible confound in our results relates to differences in stimulus density between lines, angles and rhombuses. Our stimuli were evidently not equal in this respect. A previous study has shown that neural responses can be modified by stimuli consisting of lines of different orientation outside of the cells' receptive fields (Knierim and Van Essen, 1992). However, if so, then angles and rhombuses should produce a stronger response than lines. But in our study rhombuses produced weaker responses than angles so this effect cannot be critical for this study. We also discount the possibility that factors such as the spatial frequency of our stimuli (Singh et al., 2000) or "explaining away" (Kersten et al., 2004) might account for why rhombuses produced relatively weaker responses. The spatial frequency profile of our stimuli shows that rhombuses had the highest spatial frequency components, angles intermediate ones, lines and the lowest (See Supplementary Data). Hence spatial frequency cannot explain our results because the order of spatial frequency profiles for the three forms does not match the order of the activation strength.

\section{Temporal hierarchy}

It is also worth outlining another limitation of our study which precludes us from any strong statements regarding the use of a parallel strategy. In terms of the latency of activation reported in our previous study (Shigihara and Zeki, 2013), we found that all three areas were activated within the same time frame of 27$44 \mathrm{~ms}$ when subjects viewed lines and rhombuses. This compares with early latencies of 30-50 ms for activation of V1 reported in the monkey (Maunsell and Gibson, 1992). Although the use of dynamic causal modeling (DCM) for these results strongly favored the parallel model over the hierarchical one (see Shigihara and Zeki, 2013), there still remains the possibility that our results did not detect, for technical reasons, much smaller differences in latency - in the 5-10 ms range, in activation between the three areas. It is therefore possible that an area such as V1 may have been activated by, say, $10 \mathrm{~ms}$ before an area such as V3. But in light of the evident overlap in latency of activation between these areas and the activation of $\mathrm{V} 1$ at $30-50 \mathrm{~ms}$, we must still consider similar latencies of activation as a strong pointer to the possibility of parallel processing.

\section{PARALLEL STRATEGIES IN FORM PERCEPTION: EVIDENCE FROM PSYCHOPHYSICS}

The psychophysical results of Li and Gilbert (2002) and Bell et al. (2011) have shown that there may be intermediate stages to form perception even in early visual areas, including area V1 (see review by Loffler, 2008). Our results are consistent with this and suggest that the early and intermediate stages may occur in parallel within each of the three visual areas $(\mathrm{V} 1-\mathrm{V} 3)$. On the other hand, imaging studies show that all areas extending from V1 to lateral occipital complex (LOC) respond well to global forms, leading to the suggestion that they all "integrate local elements to global shapes" (Kourtzi et al., 2003). We believe in light of our present results that they may do so not only hierarchically but also in parallel.

Taken together, these results suggest that the perceptual hierarchy of relatively simple forms is not mirrored by a strictly 
sequential neurological hierarchy as far as the time course of activation of areas V1-V3 (Shigihara and Zeki, 2013) or the strength of activation produced in them by stimuli of increasing complexity is concerned. It is now well established that a hierarchical process occurs within V1 and V2 (see for example, Alonso and Martinez, 1998; Martinez and Alonso, 2001). It would thus seem that such a hierarchical strategy for the processing of forms must be used in parallel in each of the three areas that we have studied here, and possibly in other areas of the human brain that have been shown to respond well to oriented lines and that have been implicated in form perception (Vanduffel et al., 2002; Zeki et al., 2003; Fang et al., 2005; Larsson et al., 2010; McDonald et al., 2010). Recent results suggest that a parallel strategy is also used in the object-selective lateral occipital area (Silson et al., 2013). There remains the puzzle of why it is that angles produced the strongest activation in each of the three visual areas, a problem for which we have no ready answer.

We are of course also left with the puzzle of why apparently similar processes should be used in three separate visual areas, as far as can be determined from our relatively simple stimuli. One would naturally assume that they serve ultimately different ends, but what these may be is not clear at present and must remain conjectural, as must the exact contribution that each area makes to the construction of simple forms. Overall, it would be interesting to investigate what the role of each of the two strategies-the hierarchical and the parallel-is in elaborating forms and how the two co-operate to generate forms.

\section{FUNDING}

The study was funded by the Wellcome Trust, London, UK. The funding bodies did not play a role in the design, execution, or analysis of the study.

\section{ACKNOWLEDGMENTS}

This work was supported by the Wellcome Trust. We were given invaluable assistance at various stages of this work by our colleague Samuel Schwarzkopf. We are especially grateful to Karl Friston, Stewart Shipp, and John Romaya for their critical comments on earlier versions of this manuscript.

\section{SUPPLEMENTARY MATERIAL}

The Supplementary Material for this article can be found online at: http://www.frontiersin.org/journal/10.3389/fnhum. 2014.00506/abstract

\section{REFERENCES}

Alonso, J. M., and Martinez, L. M. (1998). Functional connectivity between simple cells and complex cells in cat striate cortex. Nat. Neurosci. 1, 395-403. doi: $10.1038 / 1609$

Baldwin, M. K. L., Kaskan, P. M., Zhang, B., Chino, Y. M., and Kaas, J. H. (2012). Cortical and subcortical connections of V1 and V2 in early postnatal macaque monkeys. J. Comp. Neurol. 520, 544-569. doi: 10.1002/cne.22732

Ballard, D., Hinton, G., and Sejnowski, T. J. (1983). Parallel visual computation. Nature 306, 21-26. doi: 10.1038/306021a0

Barbur, J. L., Watson, J. D. G., Frackowiak, R. S. J., and Zeki, S. (1993). Conscious visual perception without V1. Brain 116, 1293-1302. doi: 10.1093/brain/116.6.1293

Beckers, G., and Zeki, S. (1995). The consequences of inactivating areas V1 and V5 on visual motion perception. Brain 49-60. doi: 10.1093/brain/118.1.49
Bell, J., Gheorghiu, E., Hess, R. F., and Kingdom, F. (2011). Global shape processing involves a hierarchy of integration stages. Vis. Res. 51, 1760-1766. doi: 10.1016/j.visres.2011.06.003

Benevento, L., and Rezak, M. (1976). The cortical projections of the inferior pulvinar and adjacent lateral pulvinar in the rhesus monkey (Macaca mulatta): an autoradiographic study. Brain Res. 108, 1-24. doi: 10.1016/00068993(76)90160-8

Benevento, L. A., and Yoshida, K. (1981). The afferent and efferent organization of the lateral geniculo-prestriate pathways in the macaque monkey. J. Comp. Neurol. 203, 455-474. doi: 10.1002/cne.902030309

Bullier, J., and Kennedy, H. (1983). Projection of the lateral geniculate nucleus onto cortical area V2 in the macaque monkey. Exp. Brain Res. 53, 168-172. doi: 10.1007/BF00239409

Burkhalter, A. (1993). Development of forward and feedback connections between areas V1 and V2 of human visual cortex. Cereb. Cortex 3, 476-487. doi: 10.1093/cercor/3.5.476

Cheadle, S. W., and Zeki, S. (2011). Masking within and across visual dimensions: Psychophysical evidence for perceptual segregation of color and motion. Vis. Neurosci. 28, 445-451. doi: 10.1017/S0952523811000228

Cortes, N., and Van Vreeswijk, C. (2012). The role of the pulvinar in the transmission of information in the visual hierarchy. Front. Comp. Neurosci. 6:29. doi: 10.3389/fncom.2012.00029.

Cragg, B. (1969). The topography of the afferent projections in the circumstriate visual cortex of the monkey studied by the Nauta method. Vis. Res. 9, 733-747. doi: 10.1016/0042-6989(69)90011-X

ffytche, D. H., Guy, C. N., and Zeki, S. (1995). The parallel visual motion inputs into areas V1 and V5 of human cerebral cortex. Brain 118, 1375-1394. doi: 10.1093/brain/118.6.1375

Fang, F., Murray, S. O., Kersten, D., and He, S. (2005). Orientation-tuned fMRI adaptation in human visual cortex. J. Neurophysiol. 94, 4188-4195. doi: 10.1152/jn.00378.2005

Finn, I. M., and Ferster, D. (2007). Computational diversity in complex cells of cat primary visual cortex. J. Neurosci. 27, 9638-9648. doi 10.1523/JNEUROSCI.2119-07.2007

Fries, W. (1981). The projection from the lateral geniculate nucleus to the prestriate cortex of the macaque monkey. Proc. R. Soc. Lond. B 213, 73-86. doi: 10.1098/rspb.1981.0054

Gaglianese, A., Costagli, M., Bernardi, G., Ricciardi, E., and Pietrini, P. (2012). Evidence of a direct influence between the thalamus and hMT+ independent of V1 in the human brain as measured by fMRI. Neuroimage 60, 1440-1447. doi: 10.1016/j.neuroimage.2012.01.093

Grossberg, S. (1991). Why do parallel cortical systems exist for the perception of static form and moving form? Percept. Psychophys. 49, 117-141. doi: 10.3758/BF03205033

Hegdé, J., and Van Essen, D. C. (2000). Selectivity for complex shapes in primate visual area V2. J. Neurosci. 20, RC61.

Horton, J., and Hoyt, W. (1991). Quadrantic visual field defects. Brain 114, 1703-1718. doi: 10.1093/brain/114.4.1703

Hubel, D. H., and Wiesel, T. N. (1959). Receptive fields of single neurons in the cat's striate cortex. J. Physiol. 148, 574-591.

Hubel, D. H., and Wiesel, T. N. (1962). Receptive fields, binocular interaction and functional architecture in the cat's visual cortex. J. Physiol. 160, 106-154.

Hubel, D. H., and Wiesel, T. N. (1965). Receptive fields and functional architecture in two nonstriate visual areas (18 and 19) of the cat. J. Neurophysiol. 28, 229-289.

Hubel, D., and Wiesel, T. (1977). The ferrier lecture: functional architecture of macaque monkey visual cortex. Proc. R. Soc. Lond. B 198, 1-59. doi: 10.1098/rspb.1977.0085

Ito, M., and Komatsu, H. (2004). Representation of angles embedded within contour stimuli in area V2 of macaque monkeys. J. Neurosci. 24, 3313-3324. doi 10.1523/JNEUROSCI.4364-03.2004

Kennedy, H., and Bullier, J. (1985). A double-labeling investigation of the afferent connectivity to cortical areas V1 and V2 of the macaque monkey. J. Neurosci. 5, 2815-2830.

Kersten, D., Mamassian, P., and Yuille, A. (2004). Object perception as Bayesian inference. Annu. Rev. Psychol. 55, 271-304. doi: 10.1146/annurev.psych.55. 090902.142005

Knierim, J., and Van Essen, D. (1992). Neuronal responses to static texture patterns in area V1 of the alert macaque monkey. J. Neurophysiol. 67, 961-980. 
Kourtzi, Z., Tolias, A. S., Altmann, C. F., Augath, M., and Logothetis, N. K. (2003). Integration of local features into global shapes: monkey and human FMRI studies. Neuron 37, 333-346. doi: 10.1016/S0896-6273(02)01174-1

Kwong, K. K., Belliveau, J. W., Chesler, D. A., Goldberg, I. E., Weisskoff, R. M., Poncelet, B. P., et al. (1992). Dynamic magnetic resonance imaging of human brain activity during primary sensory stimulation. Proc. Natl. Acad. Sci. U. S.A. 89, 5675-5679. doi: 10.1073/pnas.89.12.5675

Lamme, V. A., and Roelfsema, P. (2000). The distinct modes of vision offered by feedforward and recurrent processing. Trends Neurosci. 23, 571-579. doi: 10.1016/S0166-2236(00)01657-X

Larsson, J., Heeger, D. J., and Landy, M. S. (2010). Orientation selectivity of motionboundary responses in human visual cortex. J. Neurophysiol. 104, 2940-2950. doi: 10.1152/jn.00400.2010

Larsson, J., Landy, M. S., and Heeger, D. J. (2006). Orientation-selective adaptation to first- and second-order patterns in human visual cortex. J. Neurophysiol. 95, 862-881. doi: 10.1152/jn.00668.2005

Leh, E. H., Chakravarty, M. M., and Ptito, A. (2008). The connectivity of the human pulvinar: a diffusion tensor imaging tractography study. Int. J. Biomed. Imag. 2008:789539. doi: 10.1155/2008/789539

Lerner, Y., Hendler, T., Ben-Bashat, D., Harel, M., and Malach, R. (2001). A hierarchical axis of object processing stages in the human visual cortex. Cereb. Cortex 11, 287-297. doi: 10.1093/cercor/11.4.287

Li, W., and Gilbert, C. D. (2002). Global contour saliency and local colinear interactions. J. Neurophysiol. 88, 2846-2856. doi: 10.1152/jn.00289.2002

Lo, Y. T., and Zeki, S. (2014). Masking reveals parallel form systems in the visual brain. Front. Hum. Neurosci. 8:567. doi: 10.3389/fnhum.2014.00567

Loffler, G. (2008). Perception of contours and shapes: low and intermediate stage mechanisms. Vis. Res. 48, 2106-2127. doi: 10.1016/j.visres.2008.03.006

Ludbrook, J. (1991). On making multiple comparisons in clinical and experimental pharmacology and physiology. Clin. Exp. Pharmacol. Physiol. 18, 379-392. doi: 10.1111/j.1440-1681.1991.tb01468.x

Martinez, L. M., and Alonso, J. M. (2001). Construction of complex receptive fields in cat primary visual cortex. Neuron 32, 515-525. doi: 10.1016/S08966273(01)00489-5

Maunsell, J. H., and Gibson, J. R. (1992). Visual response latencies in striate cortex of the macaque monkey. J. Neurophysiol. 68, 1332-1344.

McDonald, J., Mannion, D., Goddard, E., and Clifford, C. (2010). Orientationselective chromatic mechanisms in human visual cortex. J. Vis. 10, 1-12. doi: $10.1167 / 10.12 .34$

Nandy, A. S., Sharpee, T. O., Reynolds, J. H., and Mitchell, J. F. (2013). The fine structure of shape tuning in area V4. Neuron, 78, 1102-1115. doi: 10.1016/j.neuron.2013.04.016

Ostwald, D., Lam, J. M., Li, S., and Kourtzi, Z. (2008). Neural coding of global form in the human visual cortex. J. Neurophysiol. 99, 2456-2469. doi: 10.1152/jn.01307.2007

Raiguel, S. E., Lagae, L., Gulyàs, B., and Orban, G. A. (1989). Response latencies of visual cells in macaque areas V1, V2 and V5. Brain Res. 493, 155-159. doi: 10.1016/0006-8993(89)91010-X

Riesenhuber, M., and Poggio, T. (1999). Hierarchical models of object recognition in cortex. Nature Neurosci. 2, 1019-1025. doi: 10.1038/14819

Rockland, K. S. (1992). Laminar distribution of neurons projecting from area $\mathrm{V} 1$ to V2 in macaque and squirrel monkeys. Cereb. Cortex 2, 38-47. doi: $10.1093 /$ cercor/2.1.38

Sahraie, A., Weiskrantz, L., Barbur, J. L., Simmons, A., Williams, S. C. R., and Brammer, M. L. (1997). Pattern of neuronal activity associated with conscious and unconscious processing of visual signals. Proc. Natl. Acad. Sci. U.S.A. 94, 9406-9411. doi: 10.1073/pnas.94.17.9406

Schmid, M., Panagiotaropoulos, T., Augath, M., Logothetis, N., and Smirnakis, S. (2012). Visually Driven activation in macaque areas V2 and V3 without input from the primary visual cortex. PLoS ONE 4:e5527. doi: 10.1371/journal.pone. 0005527

Schoenfeld, M. A., Noesselt, T., Poggel, D., Tempelmann, C., Hopf, J. M., Woldorff, M. G., et al. (2002). Analysis of pathways mediating preserved vision after striate cortex lesions. Ann. Neurol. 52, 814-824. doi: 10.1002/ana.10394
Sereno, M. I., Dale, A. M., Reppas, J. B., Kwong, K. K., Belliveau, J. W., Brady, T. J., et al. (1995). Borders of multiple visual areas in humans revealed by functional magnetic resonance imaging. Science, 268, 889-893. doi: 10.1126/science.7754376

Shigihara, Y., and Zeki, S. (2013). Parallelism in the brain's visual form system. Eur. J. Neurosci. 38, 3712-3720. doi: 10.1111/ejn.12371

Shipp, S., Watson, J. D. G., Frackowiak, R. S. J., and Zeki, S. (1995). Retinotopic maps in human prestriate visual cortex: the demarcation of Areas V2 and V3, Neuroimage 2, 125-132. doi: 10.1006/nimg.1995.1015

Silson, E. H., McKeefry, D. J., Rodgers, J., Gouws, A. D., Hymers, M., and Morland, A. B. (2013). Specialized and independent processing of orientation and shape in visual field maps LO1 and LO2. Nat. Neurosci. 16, 267-269. doi: 10.1038/nn.3327

Sincich, L., Park, K., Wohlgemuth, M., and Horton, J. (2004). Bypassing V1: a direct geniculate input to area MT. Nat. Neurosci. 7, 1123-1128. doi: 10.1038/nn1318

Singh, K. D., Smith, A. T., and Greenlee, M. (2000). Spatiotemporal frequency and direction sensitivities of human visual areas measured using fMRI. Neuroimage 564, 550-564. doi: 10.1006/nimg.2000.0642

Stensaas, S. S., Eddington, D. K., and Dobelle, W. H. (1974). The topography and variability of the primary visual cortex in man. J. Neurosurg. 40, 747-755. doi: 10.3171/jns.1974.40.6.0747

Tootell, R. B., Mendola, J. D., Hadjikhani, N. K., Ledden, P. J., Liu, A. K., Reppas, J. B., et al. (1997). Functional analysis of V3A and related areas in human visual cortex. J. Neurosci. 17, 7060-7078.

Vanduffel, W., Tootell, R. B. H., Schoups, A. A., and Orban, G. A. (2002). The organization of orientation selectivity throughout macaque visual cortex. Cereb. Cortex 12, 647-662. doi: 10.1093/cercor/12.6.647

Van Essen, D. C., Newsome, W. T., Maunsell, J. H., and Bixby, J. L. (1986). The projections from striate cortex (V1) to areas V2 and V3 in the macaque monkey: asymmetries, areal boundaries, and patchy connections. J. Comp Neurol. 244, 451-480. doi: 10.1002/cne.902440405

Yukie, M., and Iwai, E. (1981). Direct projection from the dorsal lateral geniculate nucleus to the prestriate cortex in macaque monkeys. J. Comp. Neurol. 201, 81-97. doi: 10.1002/cne.902010107

Zeki, S. (1969). Representation of central visual fields in prestriate cortex of monkey. Brain Res. 14, 271-291. doi: 10.1016/0006-8993(69)90110-3

Zeki, S. (1971). Cortical projections from two prestriate areas in the monkey. Brain Res. 34, 19-35. doi: 10.1016/0006-8993(71)90348-9

Zeki, S. (1976). The functional organization of projections from striate to prestriate visual cortex in the rhesus monkey. Cold Spring Harb. Symp. Quant. Biol. 40, 591-600. doi: 10.1101/SQB.1976.040.01.055

Zeki, S. (1978). Uniformity and diversity of structure and function in rhesus monkey prestriate visual cortex. J. Physiol. 277, 273-290.

Zeki, S., and ffytche, D. (1998). The Riddoch syndrome: insights into the neurobiology of conscious vision. Brain, 121, 25-45. doi: 10.1093/brain/121.1.25

Zeki, S., Perry, R., and Bartels, A. (2003). The processing of kinetic contours in the brain. Cereb. Cortex 13, 189-202. doi: 10.1093/cercor/13.2.189

Zeki, S., and Shipp, S. (1988). The functional logic of cortical connections. Nature 335, 311-317. doi: 10.1038/335311a0

Conflict of Interest Statement: The authors declare that the research was conducted in the absence of any commercial or financial relationships that could be construed as a potential conflict of interest.

Received: 17 February 2014; accepted: 23 June 2014; published online: 30 July 2014. Citation: Shigihara Y and Zeki S (2014) Parallel processing in the brain's visual form system: an fMRI study. Front. Hum. Neurosci. 8:506. doi: 10.3389/fnhum.2014.00506 This article was submitted to the journal Frontiers in Human Neuroscience.

Copyright (C) 2014 Shigihara and Zeki. This is an open-access article distributed under the terms of the Creative Commons Attribution License (CC BY). The use, distribution or reproduction in other forums is permitted, provided the original author(s) or licensor are credited and that the original publication in this journal is cited, in accordance with accepted academic practice. No use, distribution or reproduction is permitted which does not comply with these terms. 